\title{
Hydrogen Susceptibility of Nanostructured Bainitic Steels
}

\author{
MATHEW JAMES PEET and TOMOHIKO HOJO
}

Nanostructured steels with an ultimate tensile strength of 1.6 GPa were produced with austenite content varying from 0 to $35 \mathrm{vol}$ pct. The effect on the mechanical properties was assessed after saturating the steel with hydrogen. Elongation was reduced to 2 to 5 pct and UTS to 65 to 70 pct of prior value. Thermal desorption measurements confirmed the higher solubility of hydrogen in the steel with higher austenite content. The level of hydrogen saturation was found to correlate to the total area of grain boundaries rather than to the volume fraction of retained austenite.

DOI: $10.1007 / \mathrm{s} 11661-015-3221-9$

(C) The Author(s) 2015. This article is published with open access at Springerlink.com

\section{INTRODUCTION}

DELETERIOUS hydrogen is introduced into the microstructure of steel as a result of manufacture, welding, corrosion, or galvanic protection. ${ }^{[1-3]}$ High strength steels are thought to be particularly susceptible. ${ }^{[4-7]}$

Nanostructured bainitic steels possess high strength imparted by the fine bainite plates in a matrix of retained austenite. ${ }^{[8-13]}$ Isothermal transformation is the only viable method of producing such a nanostructure in bulk. ${ }^{[10,14,15]}$ These novel nanostructures result from transformation at around $473 \mathrm{~K}$ to $523 \mathrm{~K}\left(200{ }^{\circ} \mathrm{C}\right.$ to $250{ }^{\circ} \mathrm{C}$ ), with a colossal supersaturation of carbon in the austenite and high supersaturation of carbon in ferrite. $^{[16-20]}$

The large fractions of austenite possible in these steels allow improvement in mechanical properties by transformation-induced plasticity, ${ }^{[21]}$ and the presence of austenite is known to result in increased trapping of hydrogen. ${ }^{[7,22]}$ The diffusion of hydrogen at $300 \mathrm{~K}$ $\left(27^{\circ} \mathrm{C}\right)$ is also much slower $\left(2 \times 10^{8}\right.$ times $)$ in austenite than in ferrite. ${ }^{[1,23]}$ The percolating austenite structure has been observed to slow diffusion, ${ }^{[24]}$ and the effective diffusivity of ferrite is also reduced by the large number of defects present. ${ }^{[24]}$

In the current work, nanostructured steels with an ultimate tensile strength of $1.6 \mathrm{GPa}$ were produced with austenite content varying from 0 to $35 \mathrm{vol}$ pct. Electrolytic hydrogen charging to saturation was applied to characterize the maximum detriment to the mechanical properties. Thermal desorption measurements were applied to characterize the potency of austenite as a trapping site in these steels.

MATHEW JAMES PEET, Research Associate, is with the Department of Materials Science and Metallurgy, University of Cambridge, 27 Charles Babbage Road, Cambridge, CB3 0FS, U.K. Contact e-mail: mjp54@cam.ac.uk TOMOHIKO HOJO, Assistant Professor, is with the Department of Mechanical Engineering, Iwate University, Morioka, Iwate, Japan.

Manuscript submitted April 26, 2015.

Article published online November 30, 2015

\section{EXPERIMENTAL METHOD}

Tensile specimens were produced with $1.1 \mathrm{~mm}$ thickness, $6 \mathrm{~mm}$ width, and $20 \mathrm{~mm}$ length of the parallel section by electro-discharge machining from cast and rolled ingots of two compositions, Steel A with composition Fe-0.83C-1.98Mn-1.02Cr-1.57Si-1.54Co-0.24Mo wt pet and steel $\mathrm{B}$ having composition Fe-0.78C-2.02Mn1.01Cr-1.60Si-3.87Co-1.37Al-0.24Mo wt pct. The materials are from the same stock as previously developed and characterized by Garcia-Mateo et al..$^{[9,10]}$ The tensile specimens were austenitized for 30 minutes at $1223 \mathrm{~K}$ $\left(950{ }^{\circ} \mathrm{C}\right)$ in an argon tube furnace before transfer to fan-assisted oven at $563 \mathrm{~K}\left(290{ }^{\circ} \mathrm{C}\right)$ and held for 6 hours. A number of samples of steel A were tempered at $773 \mathrm{~K}$ $\left(500{ }^{\circ} \mathrm{C}\right)$ to provide comparison against a microstructure with a negligible amount of retained austenite. Previous experiments reveal the high resistance to tempering of the bainitic microstructure in these steels, ${ }^{[25]}$ and tempering at $573 \mathrm{~K}\left(300{ }^{\circ} \mathrm{C}\right)$ in this work was not sufficient to reduce the fraction of retained austenite.

Lattice parameters and volume fraction of austenite after isothermal transformation were determined by X-ray diffraction using a Phillips PW1830 diffractometer operated at $40 \mathrm{kV}$ and $40 \mathrm{~mA}$, with $10 \mathrm{~mm}$ mask, $1 / 2$ deg divergence and anti-scatter slits, and $0.2 \mathrm{~mm}$ receiving slit. Peak positions and intensities were determined using Phillips ProFit software, to derive lattice parameters and volume fractions for ferrite and austenite. ${ }^{[26]}$ Lattice parameters were related to carbon content using linear equations following previous workers. ${ }^{[27]}$

Hardness measurements were made using Vickers hardness machine using a load of $50 \mathrm{~kg}$, with three indentations made, and the error estimated from the standard deviation of the six measurements.

The hydrogen susceptibility of the steels in each condition was assessed by comparing the tensile properties before and after hydrogen charging. Hydrogen charging was achieved by spot welding samples at one end to a stainless strip with all except the gage length painted with lacquer to prevent contact with the electrolyte. The stainless steel strip was used to suspend 
the tensile samples in a solution of $2.5 \mathrm{~L}$ distilled water, $78 \mathrm{~g}$ of sodium chloride, and $7.8 \mathrm{~g}$ of ammonium thiocyanate. A voltage was applied using a constant current supply of $20 \mathrm{~mA}$ for 48 hours to produce a current density of $10 \mathrm{~A} / \mathrm{m}^{2}$. The gage length of the tensile samples formed the cathode, and a platinum wire was used as the anode.

Tensile testing was undertaken with an Instron 8501 hydraulic testing machine, with 2620-604 axial clip-on dynamic strain gage extensometer using $15 \mathrm{~mm}$ gage length at a crosshead speed of $1 \mathrm{~mm} \mathrm{~min}^{-1}$, resulting in a strain rate in the gage length of $0.022 \mathrm{~min}^{-1}$. A series of tests were started 10 minutes after charging, with the final test being complete approximately 1 hour after charging was complete.

For analysis of the hydrogen content, charging was repeated with the same conditions on spare tensile samples of the same dimensions which had been heat treated along with the mechanically tested samples. Total hydrogen content was determined by heating a small amount of material until melting. Hydrogen evolution as a function of temperature was measured using atmospheric pressure ionization mass spectrometry (APIMS) electronic gas analyzer during heating at $0.2 \mathrm{Ks}^{-1}$.

Fractography was undertaken using a JEOL JSM-6510LA electron microscope.

\section{RESULTS}

X-ray diffraction results, Table I, show that large volume fractions of austenite have been retained as a result of transformation at $563 \mathrm{~K}\left(290^{\circ} \mathrm{C}\right)$, with 35 pct austenite in alloy $\mathrm{A}$ and 30 pct in alloy $\mathrm{B}$.

Tempering at $773 \mathrm{~K}\left(500{ }^{\circ} \mathrm{C}\right)$ was applied to allow comparison against material with a low amount of retained austenite. Characterization of similarly tempered material gives confidence that the structure is likely ferrite and cementite although transition carbides are also possible. ${ }^{[26]}$ The tempering condition was selected to remove austenite while achieving a comparable hardness, and tensile properties as far as possible, to those of the as-transformed condition (as shown in Table II). Tempering alloy A at $773 \mathrm{~K} \quad\left(500{ }^{\circ} \mathrm{C}\right)$ decreased the hardness by about 5 pct and reduced the elongation from around 20 to 25 pct to 4 to 5 pct, while the ultimate tensile strength was slightly decreased (also $\approx 5$ pct) but the yield strength increased by 25 pct.
Figure 1 compares the stress-strain curves before and after hydrogen charging, and Table II summarizes the mechanical property results; in all cases, elongation was greatly reduced by saturation with hydrogen.

In the previous literature, the concept of a 'hydrogen embrittlement susceptibility factor' (HES) has been introduced as the percentage of each property lost after exposure to hydrogen. ${ }^{[28]}$ Table II compares HES as calculated from the change of yield strength, ultimate tensile strength, or elongation. Steel A in the tempered condition had the lowest susceptibility as measured by elongation HES factor, but this is due to the low initial value of elongation. A negative value of the embrittlement factor was calculated when considering the change in the area reduction, indicating a slight expansion; however, the initial and final values are of similar magnitude, and this is likely to be an artifact due to measurement errors. Steel B in the as-transformed condition retained a larger proportion of the ultimate tensile strength than steel A.

Figures 2 through 4 show the typical appearance of the fracture surfaces of the tensile samples, for evaluation of fracture mechanism. Steels A and B in the as-transformed condition showed ductility in the tensile results, and necking was observed in the tensile samples. This is consistent with the microvoid coalescence seen on the fracture surfaces of the un-tempered material. Ductility is lower in the tempered material, and fracture surface has a larger proportion of flat areas indicating a greater role of crack propagation during failure (i.e., brittle fracture).

There is a striking similarity of the fracture surfaces on the microscopic scale when comparing the as-heattreated and the hydrogen-charged material in each case, except that the introduction of hydrogen has superimposed a large amount of secondary cracking. Fracture surfaces typically incorporate features of both ductile failure and quasi-cleavage. Secondary cracking in hydrogen-charged samples exhibits a faceted appearance and can be seen to propagate in both an intergranular mode along prior austenite grain or packet boundaries and, most often, in a transgranular/intragranular mode, passing through similarly oriented regions on the scale of the bainite packets. This is common in carbide-free bainitic steels due to the packets of bainite containing plates of similar orientation, which will lead to a larger 'crystallographic grain size' and decrease the ability of the structure to resist crack propagation. ${ }^{[29,30]}$

Table I. X-ray Diffraction Results, Sample Identification in the Form Alloy-T1-T2 Where T1 and T2 are the Temperatures of Isothermal Transformation and Tempering, Respectively, Both in Kelvin

\begin{tabular}{|c|c|c|c|c|}
\hline \multirow[b]{2}{*}{ Sample } & \multicolumn{3}{|c|}{ Austenite } & \multirow{2}{*}{$\begin{array}{l}\text { Ferrite } \\
\text { LP (A) }\end{array}$} \\
\hline & Volume (pct) & LP $(\AA)$ & $C$ (wt pct) & \\
\hline A-563 & $35.1 \pm 0.1$ & $3.61650 \pm 0.002$ & $1.09 \pm 0.06$ & $2.86412 \pm 0.0003$ \\
\hline A-563-573 & $36.1 \pm 0.2$ & $3.62006 \pm 0.001$ & $1.20 \pm 0.02$ & $2.86325 \pm 0.001$ \\
\hline A-563-773 & 0 & $\mathrm{~N} / \mathrm{A}$ & $\mathrm{N} / \mathrm{A}$ & $2.86911 \pm 0.002$ \\
\hline B-563 & $30.0 \pm 0.1$ & $3.63334 \pm 0.002$ & $1.40 \pm 0.07$ & $2.87297 \pm 0.002$ \\
\hline
\end{tabular}




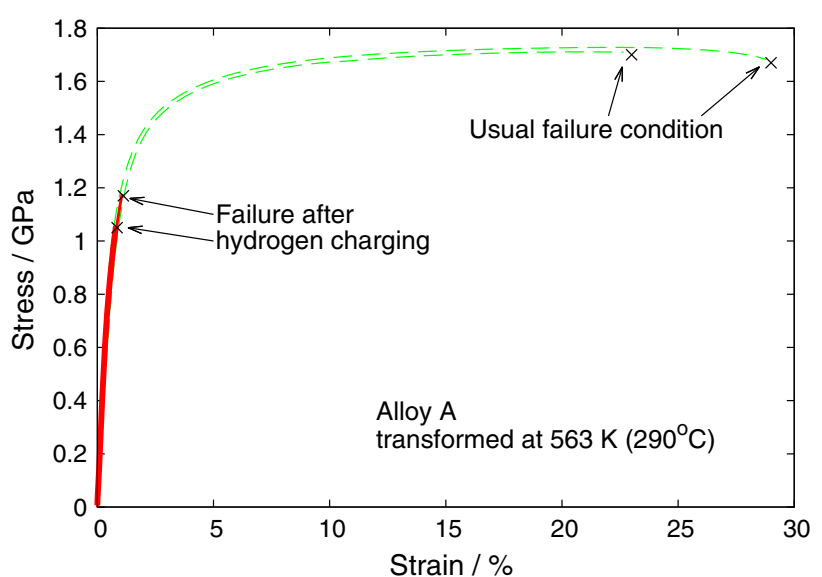

(a)

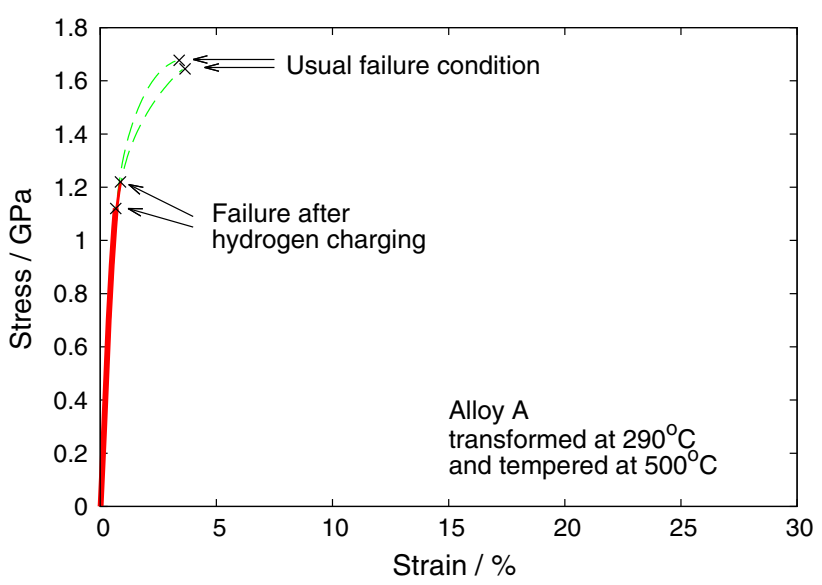

(b)

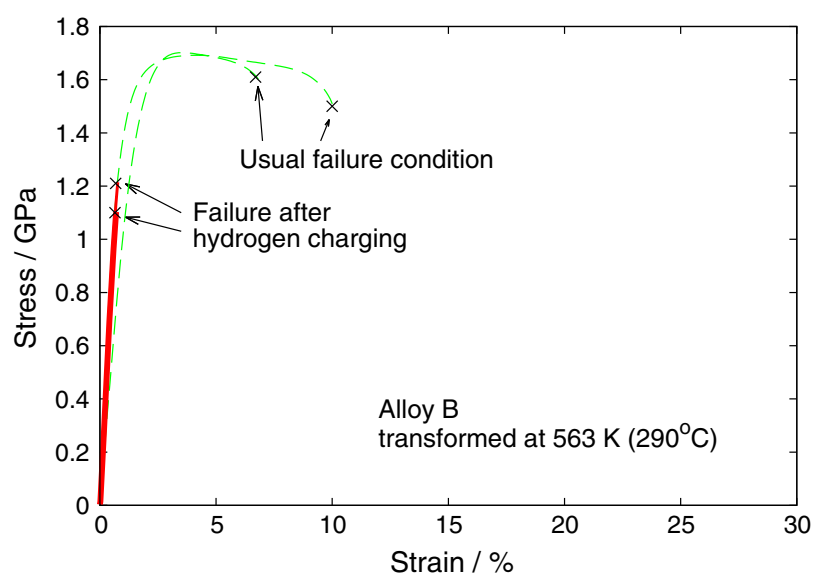

(c)

Fig. 1-Results of tensile testing, showing the reduction of elongation by hydrogen charging.

Comparing fracture surfaces for alloy $\mathrm{A}$, in the as-transformed condition the fracture surface shows evidence of microvoid coalescence, Figure 2(a). This sample exhibited 20 pct of uniform elongation and slight necking before failure. After hydrogen charging, the fracture surface, Figure 2(b), is more typical of that expected from brittle cleavage failure, and could be characterized as quasi-cleavage with failure both through bainite packets and at the packet boundaries. Despite the elongation being only 0.4 pct in this condition, there does still seem to be evidence of some areas of microvoid coalescence on the fracture surface.

In the tempered condition (AT, Figure 3), there is very little difference in the appearance in the two conditions except the superposition of cracking in the hydrogen-charged material. In both cases, the fracture surfaces are best classified as quasi-cleavage.

In alloy B, both fracture surfaces (Figure 4) show evidence of both ductile failure by microvoid coalescence and some faceted appearance typical of quasi-cleavage. This material exhibited clear evidence of necking before failure in the as-transformed material.

Comparison of Figures 4(a) and (b) shows a remarkable similarity in the nature of the fracture surface in alloy $\mathrm{B}$ in the as-transformed condition, considering the scale of microvoids. In alloy A, also transformed at $563 \mathrm{~K}\left(290{ }^{\circ} \mathrm{C}\right)$ after hydrogen charging, the surface has a more faceted appearance than without hydrogen. The length scale of the facets is similar to that of the bainite packets (rather than the prior austenite grain size or the plate size). Accompanying the faceted area, there are many regions which have a more ductile appearance.

As can be noted from the fractographs, the position of cracking on the fracture surface was different in each of the materials tested, from the surface in the as-transformed alloy $\mathrm{A}$, along the center line of fracture surface in tempered alloy A, and with more complicated cracking along center but with radial cracks toward corners in alloy B fracture surface. It is not known how reproducible the position of cracking would be if the experiments were repeated several times, or if the position of these secondary cracks has any influence on mechanical properties.

Although on a microscopic scale ductility is indicated by the fracture surface of the hydrogen-charged samples, the samples had very little elongation before failure. Macroscopically, the fracture surfaces of alloys $A$ and B in charged condition are very different, Figure 5. Alloy B has complex fracture surface with flat areas indicating cleavage at edges of the sample and the more ductile area shown in previous figures occurring at the center. In contrast, alloy A had similar appearance on the entire fracture surface apart from the appearance of cracking in certain locations. Failure occurred at stress levels above $1 \mathrm{GPa}$, so large amounts of energy are released during tensile failure, and it is therefore possible that the secondary cracking observed could occur as part of the fracture process and not necessarily as part of fracture initiation.

Regarding the level of hydrogen absorption, alloys A and $\mathrm{B}$ containing retained austenite absorbed more hydrogen than alloy $\mathrm{A}$ in tempered condition (AT) which had no retained austenite.

The peaks of the hydrogen evolution curve of alloys A and $\mathrm{B}$ are shifted to higher temperature compared with that of the tempered material. The presence of retained austenite is clearly associated with the capacity to store hydrogen as there is a large effect on the total amount of absorption. A larger amount of hydrogen could be 
Table II. Tensile Test Results, A-Alloy A Transformed at $563 \mathrm{~K}\left(290^{\circ} \mathrm{C}\right)$, AT-Subsequently Tempered at $773 \mathrm{~K}\left(500{ }^{\circ} \mathrm{C}\right)$, B-Alloy B Transformed at $563 \mathrm{~K}\left(290^{\circ} \mathrm{C}\right)$, and $+\mathrm{H}$ Indicates Hydrogen-Charged Conditions

\begin{tabular}{|c|c|c|c|c|c|c|c|c|c|c|}
\hline \multirow[b]{2}{*}{ Alloy } & & \multirow[b]{2}{*}{$\mathrm{TS}(\mathrm{MPa})$} & \multirow[b]{2}{*}{ YS (MPa) } & \multirow[b]{2}{*}{ TEl (pct) } & \multirow[b]{2}{*}{$\mathrm{UEl}(\mathrm{pct})$} & \multirow[b]{2}{*}{ RA (pct) } & \multirow[b]{2}{*}{ Hardness (HV50) } & \multicolumn{3}{|c|}{ HES, pct } \\
\hline & & & & & & & & $(\mathrm{RA})$ & (TEl) & (TS) \\
\hline \multirow[t]{4}{*}{ A } & & 1710 & 1090 & 21.4 & 20.0 & 24 & $512 \pm 6$ & 60.8 & 98.4 & 35.1 \\
\hline & & 1729 & 891 & 28.0 & 25.0 & 40 & & & & \\
\hline & $+\mathrm{H}$ & 1178 & 889 & 0.4 & 0.4 & 14 & & & & \\
\hline & & 1055 & 909 & 0.4 & 0.4 & 11 & & & & \\
\hline \multirow[t]{4}{*}{ AT } & & 1686 & 1212 & 2.25 & 2.25 & 9.0 & $493 \pm 9$ & -31.1 & 94.8 & 29.2 \\
\hline & & 1617 & 1273 & 2.6 & 2.6 & 11 & & & & \\
\hline & $+\mathrm{H}$ & 1220 & 1220 & 0.2 & 0.2 & 13 & & & & \\
\hline & & 1119 & 1119 & 0.05 & 0.05 & 12 & & & & \\
\hline \multirow[t]{4}{*}{ B } & & 1715 & 1372 & 9.1 & 4.0 & 37 & $518 \pm 8$ & 71.4 & 98.6 & 19.2 \\
\hline & & 1702 & 1350 & 5.3 & 1.7 & 44 & & & & \\
\hline & $+\mathrm{H}$ & 1300 & 1300 & 0.1 & 0.1 & 12 & & & & \\
\hline & & 1460 & 1460 & 0.1 & 0.1 & 11 & & & & \\
\hline
\end{tabular}

TS: tensile stress; YS: yield stress; TEl: total elongation; UEl: uniform elongation; RA: reduction in area.

Hydrogen embrittlement susceptibility (HES) for each property $(R A, T E l, T S)$ expresses the hydrogen-charged behavior in terms of initial property, e.g., considering the reduction in area $\mathrm{HES}_{\mathrm{RA}}=100 \times\left(1-\mathrm{RA}_{i} / \mathrm{RA}_{0}\right)$, where $\mathrm{RA}_{i}$ andRA $\mathrm{A}_{0}$ are the instantaneous (charged) value and initial value, respectively.

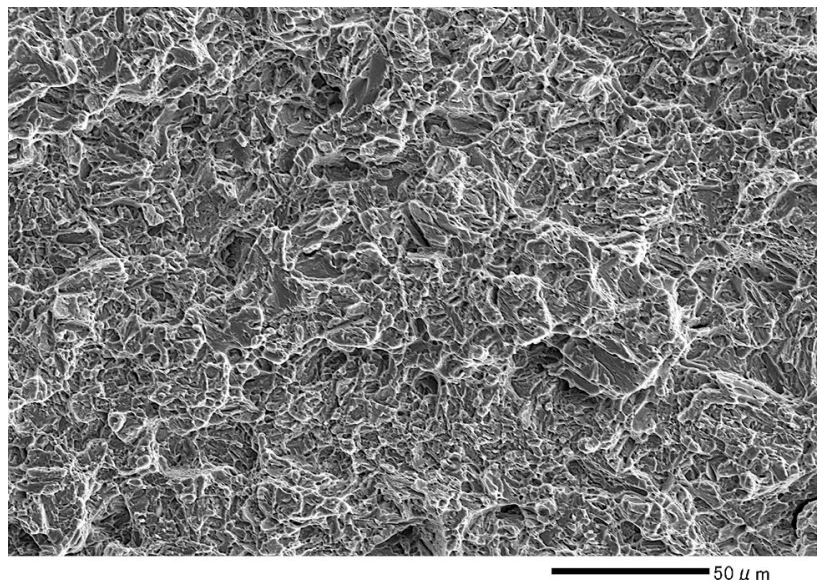

(a)

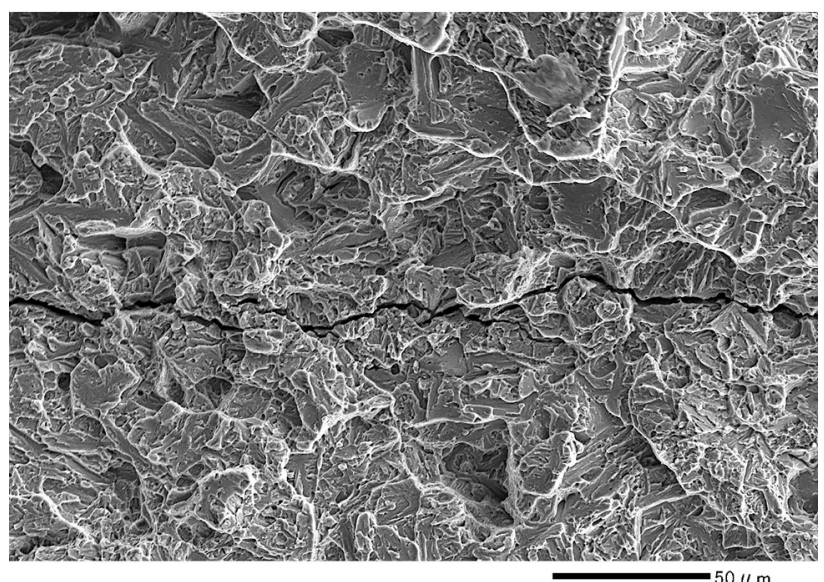

(b)

Fig. 2-Fractographs of (a) Steel A transformed at $563 \mathrm{~K}\left(290^{\circ} \mathrm{C}\right)$ and $(b)$ after hydrogen charging.

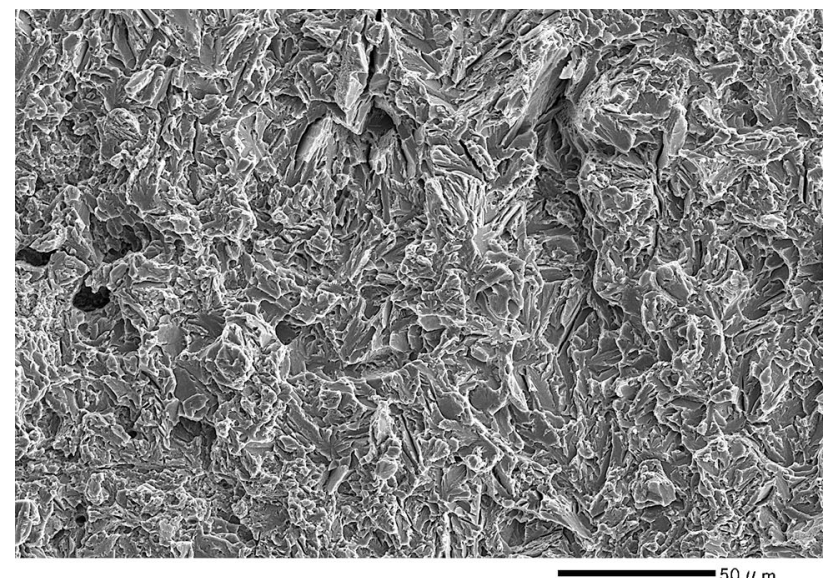

(a)

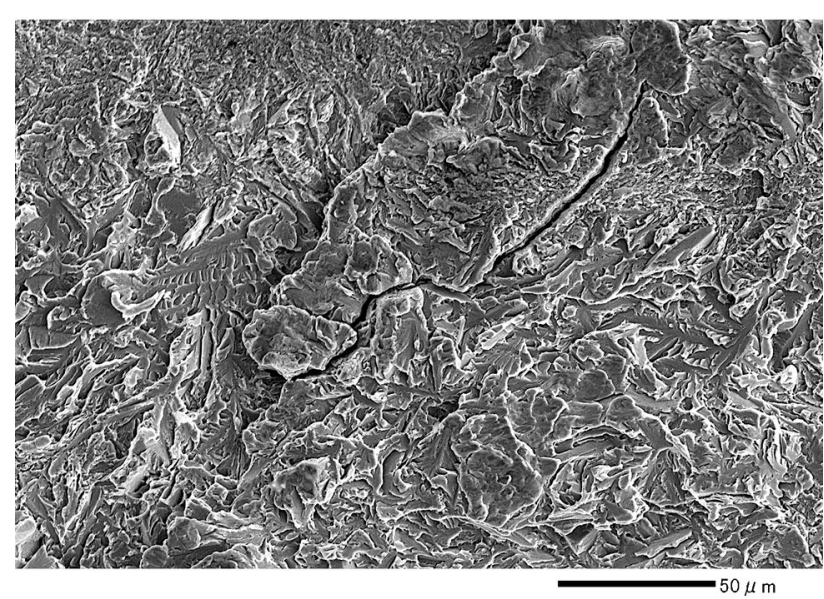

(b)

Fig. 3-Fractographs of (a) Steel A transformed at $563 \mathrm{~K}\left(290{ }^{\circ} \mathrm{C}\right)$ and tempered at $773 \mathrm{~K}\left(500{ }^{\circ} \mathrm{C}\right)$ and $(b)$ after hydrogen charging. 


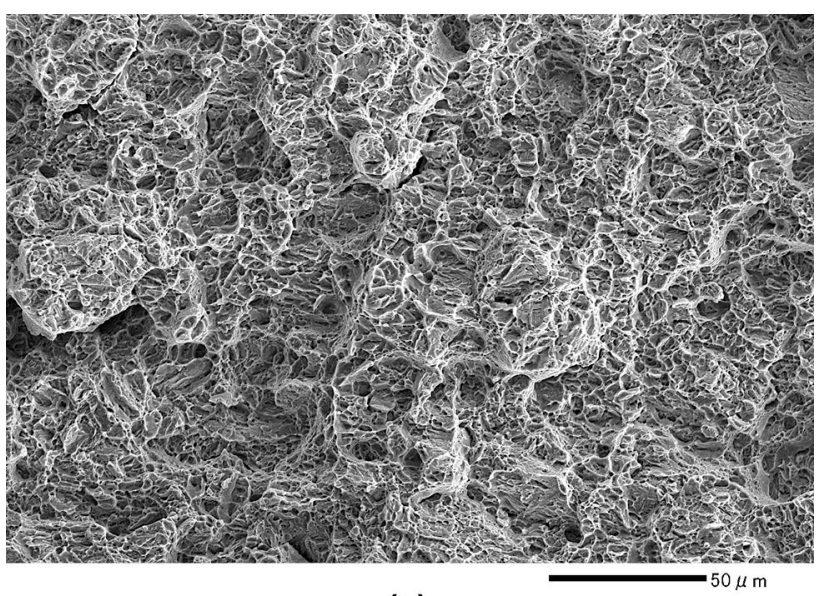

(a)

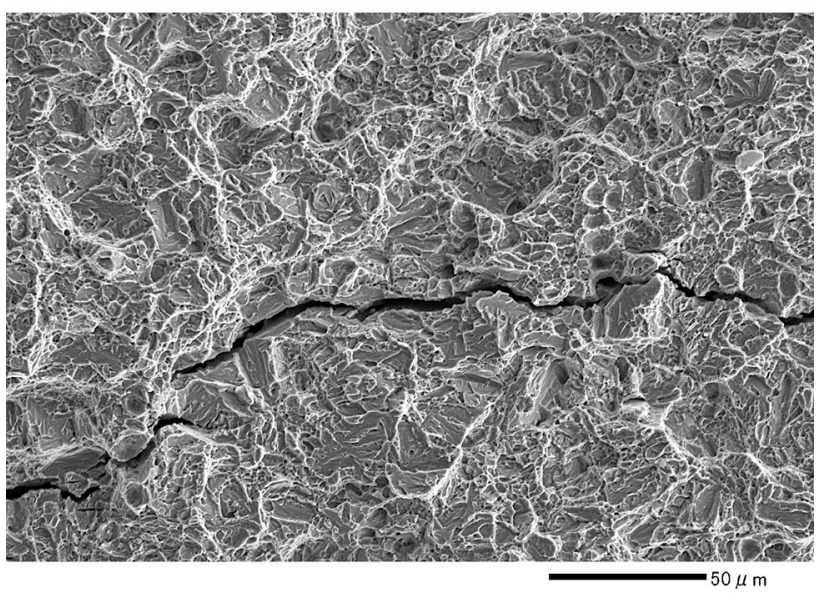

(b)

Fig. 4-Fractographs of (a) Steel B transformed at $563 \mathrm{~K}\left(290^{\circ} \mathrm{C}\right)$ and $(b)$ after hydrogen charging. Tensile fracture surfaces of Steel A in tempered condition.

stored in the austenite or at austenite-ferrite boundaries. Since each evolution curve took the form of a single peak (or indistinguishable overlapping peaks), the amounts of diffusible hydrogen were defined as hydrogen evolved at temperatures below $473 \mathrm{~K}\left(200^{\circ} \mathrm{C}\right)$. Distinguishing diffusible hydrogen in this way should be considered quite arbitrary, but it is not possible to distinguish from the curves observed if there is a single distribution of trapping sites or several types of sites. As shown in Table III and Figure 6, the ratio of diffusible to total hydrogen is almost constant.

In the present study, it is not strictly possible to relate the evolution curve to changes occurring in the microstructure during heating without further characterization of the samples. However, from previous work examining the resistance to tempering, it seems most likely that the evolution of hydrogen during heating was not dependent on changes in the microstructure but dominated by the effect of the strength of trapping sites. As observed by X-ray diffraction, in this steel austenite is retained at a similar volume fraction even after heating to $573 \mathrm{~K}\left(300{ }^{\circ} \mathrm{C}\right)$ and holding for 5 hours (Table I). So evolution of hydrogen seen in Figure 7 is

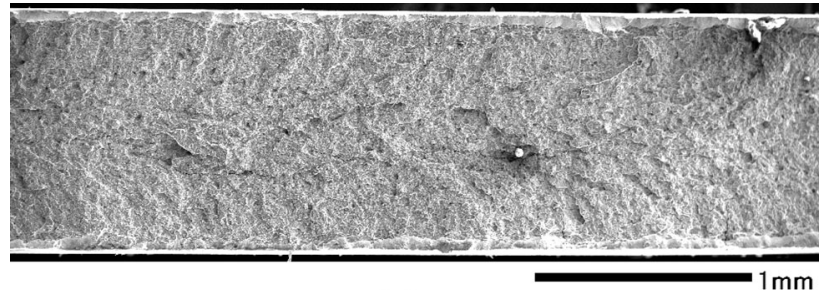

(a)

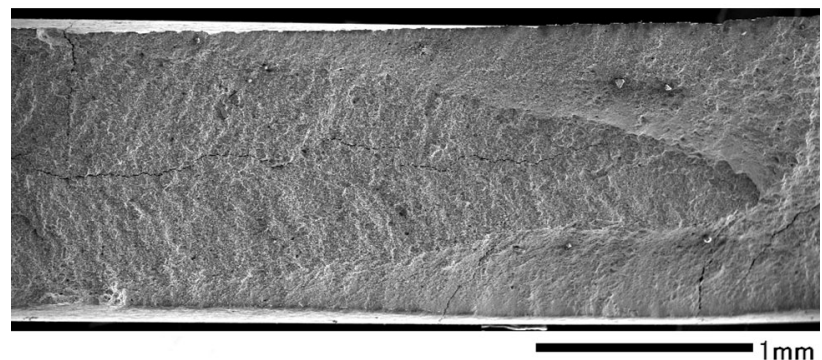

(b)

Fig. 5-Fracture surfaces of hydrogen-charged samples at lower resolution, showing the proportion of fracture surface which sheared. Images show approximately half the fracture surface with outer edge close to the image in right-hand side. Steel B exhibited a greater amount of shearing and both samples exhibit cracking after hydrogen charging.

unlikely to be related to changes in phase fractions of austenite below this temperature.

The samples with retained austenite both had higher amounts of diffusible and non-diffusible hydrogen than the tempered sample, and the simple correlation shows increased storage depending on the amount of austenite. However, alloy B with a slightly lower amount of retained austenite has a greater storage capacity than alloy A. The most likely explanation is that the hydrogen storage is associated with the larger area of interfaces introduced into the steel during transformation. Although the ferrite plate size is expected to be broadly similar as a result of transformation at the same temperature, previous results comparing alloy A with an alloy of composition Fe-0.78C-1.49Si-1.95Mn-0.97Cr$0.24 \mathrm{Mo}-0.99 \mathrm{Al}-1.60 \mathrm{Co}-0.02 \mathrm{P}-0.02 \mathrm{~S}$ wt pet transformed at $573 \mathrm{~K}\left(300{ }^{\circ} \mathrm{C}\right)$ demonstrated that alloying with $1.6 \mathrm{Co}-1 \mathrm{Al}$ caused the bainite plate size to reduce from 57 to $53 \mathrm{~nm} .{ }^{[10]}$ Alloy B in this paper has a higher level of $3.87 \mathrm{Co}-1.37 \mathrm{Al} \mathrm{wt}$ pct, and this can be expected to cause further reduction in the plate thickness due to additional strengthening of the austenite present during transformation. ${ }^{[1]}$ Given the similarity in the transformation temperature to that previously extensively characterized, it is reasonable to assume a 10 pct reduction in plate width between alloys A and B transformed at $563 \mathrm{~K}\left(290{ }^{\circ} \mathrm{C}\right)$ and therefore calculate approximately the relative difference in surface area per unit volume $\left(S_{\mathrm{V}}\right)$ between the different alloys and heat treatments. The amount of boundary surface area per unit volume of steel is proportional to the bainitic ferrite plate size and the volume fraction of ferrite $V_{\alpha}$ (Table I).

$$
\frac{S_{\mathrm{VA}}}{S_{\mathrm{VB}}}=\frac{\left(1 / t_{\mathrm{A}}\right) V_{\alpha \mathrm{A}}}{\left(1 / t_{\mathrm{B}}\right) V_{\alpha \mathrm{B}}}=\frac{\left(1 / t_{\mathrm{A}}\right) \times 0.649}{\left(1 / 0.9 t_{\mathrm{A}}\right) \times 0.7}=0.834
$$


Table III. Determination of Hydrogen Concentrations, Alloys A and B Transformed at $563 \mathrm{~K}\left(290{ }^{\circ} \mathrm{C}\right)$, AT-Alloy A Tempered at $773 \mathrm{~K}\left(500{ }^{\circ} \mathrm{C}\right)$

\begin{tabular}{lcccc}
\hline & Diffusible $H(\mathrm{ppmw})$ & Total $H(\mathrm{ppmw})$ & Total $H / V F_{\gamma}(\mathrm{ppmw})$ & Total $H / V F_{\alpha}(\mathrm{ppmw})$ \\
\hline A & 4.1 & 7.1 & 20.2 & 10.93 \\
AT & 1.8 & 3.0 & N/A & 3.0 \\
B & 5.2 & 8.5 & 28.3 & 12.14 \\
\hline
\end{tabular}

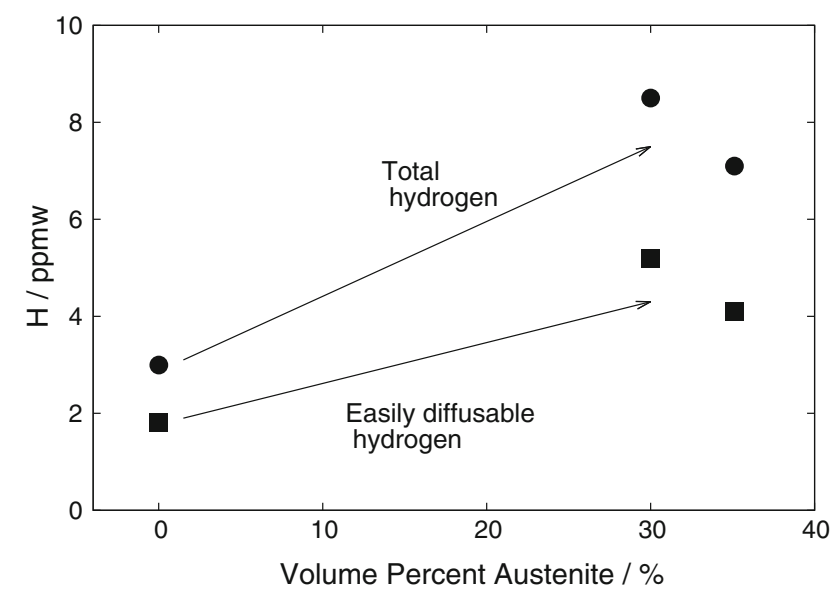

Fig. 6-Results of hydrogen analysis; the total hydrogen and the diffusible hydrogen are greater in material with a large volume fraction of retained austenite.

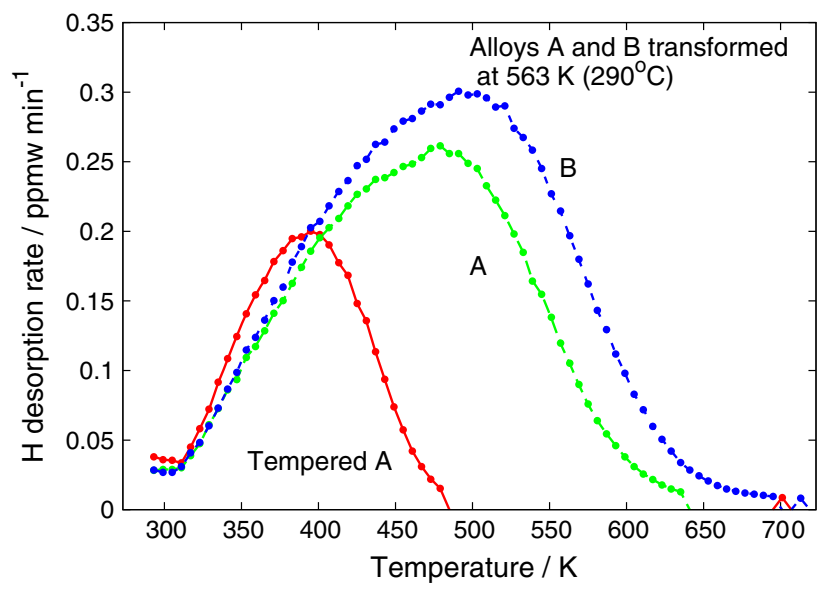

Fig. 7-Comparison of evolution of hydrogen during heating for the relevant alloys and heat treatments.

$$
\frac{H_{\mathrm{A}}}{H_{\mathrm{B}}}=\frac{7.1}{8.5}=0.835
$$

where $S_{\mathrm{VA}}$ and $S_{\mathrm{VB}}$ are the surface area per unit volume of grain boundaries in samples $\mathrm{A}$ and $\mathrm{B}$, respectively. $H_{\mathrm{A}}$ and $H_{\mathrm{B}}$ are the total hydrogen contents, $t_{\mathrm{A}}$ and $t_{\mathrm{B}}$ are the thicknesses of the bainite plates, and $V_{\alpha \mathrm{A}}$ and $V_{\alpha \mathrm{B}}$ are the volume fractions of ferrite in samples $\mathrm{A}$ and $\mathrm{B}$, respectively.

This also explains the lower storage capacity of the tempered material, since the removal of austenite from between the plates will approximately halve the area of grain boundaries per unit volume, while the storage capacity reduced to 0.42 of that in the as-transformed state. The tempering treatment applied is sufficient in this alloy to remove the retained austenite but not sufficient to subsequently coarsen the ferrite, and previous work shows that coarsening occurs after the austenite has decomposed and is associated with a large drop in hardness. ${ }^{[21,25,26,32]}$

These calculations support a correlation between the amount of hydrogen at saturation and the predicted grain boundary surface area per unit volume, rather than simply to the volume fraction of austenite (see Table III). As a result of the displacive transformation to carbide - free bainite, the grain boundaries will be predominantly of a single orientation relationship. The austenite/bainitic ferrite interface is also associated with large dislocation densities in the austenite and ferrite, which are known to be trapping sites for hydrogen.

\section{DISCUSSION}

Transformation to a nanostructure of bainitic ferrite and retained austenite has resulted in a large capacity for hydrogen trapping. The saturation levels of 7.1 to 8.5 ppmw can be expected to provide improved resistance to hydrogen embrittlement when low levels of hydrogen are introduced. In this saturated condition, the elongation was greatly reduced; however, the large trapping capacity may be advantageous in service conditions, and the presence of austenite can also be expected to lower the rate of hydrogen diffusion which may also further delay fracture. With regard to the trapping of hydrogen, it should be noted that the strength of the trapping site and location may also be expected to be important. It may be that the introduction of strong trapping sites associated with carbides would be more beneficial in lowering diffusible hydrogen in the matrix.

Solano-Alvarez et al. have conducted thermal desorption experiments in 52100 steel, transformed to martensite with 12 pct retained austenite and carbides present. After saturation with hydrogen, $7 \mathrm{ppmw}$ was desorbed by heating to $673 \mathrm{~K}$, increasing to more than 9 ppmw after introducing micro-cracks by heat treatment; this suggests that incoherent phases can be used to introduce strong trapping sites. ${ }^{[32,33]}$

In the evolution curves observed, the presence of austenite is associated with a shift in the desorption peak to around $498 \mathrm{~K}\left(225^{\circ} \mathrm{C}\right)$ from $383 \mathrm{~K}\left(110^{\circ} \mathrm{C}\right)$. At saturation, the diffusible hydrogen level was similar in the three conditions observed, with evolution curve similar below $383 \mathrm{~K}\left(110^{\circ} \mathrm{C}\right)$. It is possible to introduce 
stronger trapping sites by the introduction of appropriate carbide particles, ${ }^{[34]}$ and in this case the fine scale of the bainitic microstructure could be beneficial in further work by allowing a very fine dispersion of carbides due to precipitation at the plate boundaries. ${ }^{[25,26]}$

The three conditions of the steel examined suffered from low elongation after hydrogen embrittlement, reducing to 2 to 5 pct of the previous value. Steel A in the tempered condition has a lower calculated hydrogen embrittlement factor, but this is due to the lower initial elongation, rather than better absolute value.

There is a striking similarity of the fracture surfaces at high resolution when comparing the as-heat-treated and the hydrogen-charged material in each case, except that the material where hydrogen has been introduced has in addition a large amount of secondary cracking. Microplasticity of the brittle surface has previously been claimed to be evidence of the hydrogen-enhanced plasticity mechanism. ${ }^{[35]}$ However, cleavage in iron is well known to be associated with microscopic plasticity. ${ }^{[36]}$ In these materials, the microplasticity was evident irrespective of the presence of hydrogen, and voids are present at the scale of 1 micrometer due to the high strength.

In TRIP-aided steels, correlation has been observed between total hydrogen concentration after charging and the initial volume fraction of retained austenite. ${ }^{[3]}$ Also, in TRIP-aided steels with bainitic ferrite matrix the addition of aluminum has been observed to increase the mechanical stability of austenite (with regard to hydrogen-assisted or stress-assisted transformation to martensite) by increasing its enrichment in carbon. ${ }^{[37]} \mathrm{A}$ similar effect has been observed in high-manganese austenitic steels, where the effect of aluminum on the stacking fault energy increases the resistance to hydrogen embrittlement by reducing the tendency to form twin-boundary sites susceptible to embrittlement. ${ }^{[22]}$

The high volume fraction of austenite can be expected to increase the resistance to hydrogen embrittlement by introducing trapping sites either in the austenite, or in the form of the large area of interface between the fine bainite plates and thin films of austenite.

Correlation of the total hydrogen content after saturation and the grain boundary surface area per unit volume indicates that this is the preferred location for trapping. This suggests that greater trapping should be observed in carbide-free bainitic steels with smaller bainite plate size, e.g., by transformation at lower temperature or change of alloy content, since a larger density of boundaries can be introduced.

It is possible that this trapping occurs in the austenite due to higher solubility limit, or at ferrite-austenite boundaries, ${ }^{[38]}$ perhaps a result of the lower diffusivity in austenite, or the greater disorder at the boundary. Previous work has demonstrated that trapped hydrogen is rendered innocuous, ${ }^{[39]}$ and others have developed strategies with the aim of reducing the amount of diffusible hydrogen, for example by engineering of carbides. ${ }^{[34,40,41]}$ It is expected that austenite may contribute to the trapping, but the strength of the various trapping sites can also be expected to be of importance to the amount of diffusible hydrogen present.
Steels with a trapping capacity $>3$ parts per million by weight (ppmw) are expected to have excellent resistance to hydrogen embrittlement. ${ }^{[5,42]}$ In this paper, we have demonstrated that austenite content above $30 \mathrm{vol}$ pct results in trapping above 7 ppmw, and observed the large deterioration in properties that occurs when the steel is saturated in hydrogen. However, hydrogen susceptibility at levels expected from environmental exposure has not been assessed. In service conditions, permeating retained austenite may be expected to aid resistance to hydrogen by lowering the diffusion rate of hydrogen through the microstructure, thereby slowing absorption.

A concern has been that retained austenite may lead to uptake of hydrogen during processing, leading to embrittlement-specifically in the case of intercritical annealing and galvanizing of sheet steels as used in the automotive industry. De Cooman has highlighted the fact that hydrogen embrittlement of transformation-induced plasticity (TRIP) aided steels has only been observed as a result of hydrogen charging experiments, ${ }^{[43,44]}$ conditions unlikely to occur in automotive applications $^{[45]}$ and that the presence of hydrogen in the atmosphere during annealing does not necessarily result in increased hydrogen content of the steel, and hardly alters tensile properties in a range of TRIP-aided steels with yield strength 500 to $700 \mathrm{MPa}$ and tensile strength 700 to $960 \mathrm{MPa}^{[45]}$

\section{CONCLUSIONS}

Despite the large quantity of austenite, there was no demonstrated advantage conferred to the prevention of embrittlement after saturation with hydrogen.

After saturation with hydrogen, fracture surfaces exhibited greater tendency toward quasi-cleavage although areas exhibiting plasticity were also observed.

As could be expected from the higher solubility of hydrogen in austenite, the presence of austenite in the structure was associated with greater hydrogen contents after charging. However, our analysis suggests a stronger correlation between the total hydrogen content and the total area of austenite-ferrite boundaries. A prediction based on this observation is that transformation at lower temperatures should result in greater ability for trapping of hydrogen for the same austenite volume fraction.

\section{ACKNOWLEDGMENTS}

It is gratifying to thank Professor A. L. Greer and Professor Sir H.K.D.H. Bhadeshia for provision of laboratory equipment and funds to carry out this work.

\section{OPEN ACCESS}

This article is distributed under the terms of the Creative Commons Attribution 4.0 International License (http://creativecommons.org/licenses/by/4.0/), which permits unrestricted use, distribution, and 
reproduction in any medium, provided you give appropriate credit to the original author(s) and the source, provide a link to the Creative Commons license, and indicate if changes were made.

\section{ELECTRONIC SUPPLEMENTARY MATERIAL}

The online version of this article (doi: 10.1007/s11661-015-3221-9) contains supplementary material, which is available to authorized users.

\section{REFERENCES}

1. J.P. Hirth: Metall. Trans. A, 1980, vol. 11A, p. 861.

2. I.M. Bernstein: in Hydrogen Effects in Metals, I.M. Bernstein and A.W. Thompson, eds., Metallurgical Society of AIME, Warrendale, 1996, pp. 3-11.

3. H.K.D.H. Bhadeshia: Prog. Mater Sci., 2012, vol. 57, pp. 268-435.

4. H. Okada: Stress Corrosion Cracking and Hydrogen Embrittlement of Iron Base Alloys, NACE-5, Unieux-Firminy, France, June 12-16, 1973, J. Hochmann, J. Slater, R.D. McCright, and R.W. Staehle (eds.), NACE, Houston, 1977, Library of Congress Number 77084102, pp. 124-134.

5. T. Tarui and S. Yamasaki: J. Iron Steel Inst. Jpn., 2002, vol. 88, pp. $612-19$.

6. S. Matsuyama: In Delayed Fracture, Nikkan Kogyo Shinbun Ltd, Tokyo, 1989.

7. T. Hojo, S. Song, K. Sugimoto, A. Nagasaka, S. Ikeda, H. Akamizu, and M. Mayuzumi: Tetsu-to-Hagané, 2004, vol. 90, pp. $177-82$.

8. F.G. Caballero, H.K.D.H. Bhadeshia, K.J.A. Mawella, D.G. Jones, and P. Brown: Mater. Sci. Technol., 2002, vol. 18, pp. 279-84.

9. C. Garcia-Mateo, F.G. Caballero, and H.K.D.H. Bhadeshia: $J$. Phys., 2003, vol. 112, pp. 17-25.

10. C. Garcia-Mateo, F.G. Caballero, and H.K.D.H. Bhadeshia: ISIJ Int., 2003, vol. 43 (11), pp. 1821-25.

11. C. Garcia-Mateo, F.G. Caballero, and H.K.D.H. Bhadeshia: ISIJ Int., 2003, vol. 43 (8), pp. 1238-43.

12. C. Garcia-Mateo, F.G. Caballero, and H.K.D.H. Bhadeshia: Mater. Sci. Forum, 2005, vols. 500-501, pp. 495-502.

13. M. Peet, P. Hill, M. Rawson, S. Wood, and H.K.D.H. Bhadeshia: Mater. Sci. Technol., 2011, vol. 27 (1), pp. 119-23.

14. H.K.D.H. Bhadeshia: Mater. Sci. Technol., 2005, pp. 1293-1302.

15. H.S. Hasan, M. Peet, H.K.D.H. Bhadeshia, S. Wood, and E. Booth: Mater. Sci. Technol., 2010, vol. 26, pp. 453-56.

16. M.J. Peet, S.S. Babu, M.K. Miller, and H.K.D.H. Bhadeshia: Scr. Mater., 2004, vol. 50, pp. 1277-81.

17. S.S. Babu, E.D. Specht, S.A. David, E. Karapetrova, P. Zschack, M. Peet, and H.K.D.H. Bhadeshia: Metall. Mater. Trans. A, 2005, vol. 36A, pp. 3281-89.
18. H.J. Stone, M.J. Peet, H.K.D.H. Bhadeshia, P.J. Withers, S.S. Babu, and E.D. Specht: Proc. R. Soc. London Ser. A, 2008, pp. 1009-27.

19. F.G. Caballero, M.K. Miller, A.J. Clarke, and C. Garcia-Mateo: Scr. Mater., 2010, vol. 63, pp. 442-45.

20. C.N. Hulme-Smith, M.J. Peet, I. Lonardelli, A.C. Dippel, and H.K.D.H. Bhadeshia: Mater. Sci. Technol., 2015, vol. 31 (2), pp. 254-56.

21. H.S. Hasan, M.J. Peet, M.-N. Avettand-Fenoel, and H.K.D.H. Bhadeshia: Mater. Sci. Eng. A, 2014, vol. 615, pp. 340-47.

22. J.H. Ryu, S.K. Kim, C.S. Lee, D.-W. Suh, and H.K.D.H. Bhadeshia: Proc. R. Soc. A, 2013, vol. 469, p. 20120458.

23. X. Sun, J. Xu, and Y. Li: Mater. Sci. Eng. A, 1989, vol. 114, pp. 179-87.

24. L. Fielding, E.J. Song, D.-K. Han, H. Bhadeshia, and D.-W. Suh: Proc. R. Soc. Lond. A, 2015, vol. 470 (2168), p. 20140108.

25. C. Garcia-Mateo, M.J. Peet, F.G. Caballero, and H.K.D.H. Bhadeshia: Mater. Sci. Technol., 2004, vol. 20, pp. 814-18.

26. M.J. Peet. PhD Thesis, University of Cambridge, 2010. http://mathewpeet.org/thesis/.

27. H.K.D.H. Bhadeshia, S.A. David, J.M. Vitek, and R.W. Reed: Mater. Sci. Technol., 1991, vol. 7 (8), pp. 686-98.

28. W. Urushihara, F. Yuse, T. Nakayama, Y. Namimura, and N. Ibaraki: Kobe Steel Eng. Rep., 2002, vol. 52 (3), pp. 57-61.

29. P. Yan, Ö.E. Güngör, P. Thibaux, and H.K.D.H. Bhadeshia: Sci. Technol. Weld. Join., 2010, vol. 15, pp. 137-41.

30. P. Yan, Ö.E. Güngör, P. Thibaux, and H.K.D.H. Bhadeshia: $A d v$. Mater. Res., 2010, vols. 89-91, pp. 651-56.

31. S.B. Singh and H.K.D.H. Bhadeshia: Mater. Sci. Eng., A, pages 72-79, 1998.

32. H.S. Hasan, M.J. Peet, and H.K.D.H. Bhadeshia: Int. J. Mater. Res., 2012, vol. 103, pp. 1319-24.

33. W. Solano-Alvarez, E.J. Song, D.K. Han, D.W. Suh, and H.K.D.H. Bhadeshia: Metall. Mater. Trans. A, 2015, vol. 46A, pp. 665-73.

34. S. Yamasaki and H.K.D.H. Bhadeshia: Mater. Sci. Technol., 2003, vol. 19 , pp. $723-31$

35. C.D. Beacham: Metall. Trans., 1972, vol. 3, pp. 437-51

36. J.F. Knott: Fundamentals of Fracture Mechanics, Butterworths, London, 1981

37. T. Hojo, K. Sugimoto, Y. Mukai, and S. Ikeda: ISIJ Int., 2008, vol. 48 (6), pp. 824-29.

38. J.L. Gu, K.D. Chang, H.S. Fang, and B.Z. Bai: ISIJ Int., 2002, vol. 42 , p. 1560 .

39. K. Takai and R. Watanuki: ISIJ Int., 2002, vol. 43 (4), pp. 520-26.

40. T. Kushida, N. Kuratomi, T. Kudoh, H. Matumoto, T. Tsumura, and F. Nakasato: Tetsu-to-Hagané, 1996, vol. 82, pp. 297-302.

41. M. Kubota, T. Tarui, S. Yamasaki, and T. Ochi: Technical Report 91, 2005

42. S. Yamasaki, M. Kubota, and T. Tarui: Nippon Steel Tech. Rep., 1999, vol. 80 , pp. 50-55.

43. M. De Meyer, K. De Wit, and B.C. De Cooman: Steel Res. Int., 2000, vol. 71 (12), pp. 511-18

44. T.B. Hildich, S.-B. Lee, J.G. Speer, and D.K. Matlock: Proceedings of SAE 2003 World Congress and Exhibition, Detroit, MI, 2003.

45. B.C. De Cooman: Curr. Opin. Solid State Mater. Sci., 2004, vol. 8 , pp. 285-303. 